\title{
EIN NOSTALGISCHER SPÖTTER / UM GALHOFEIRO NOSTÁLGICO
}

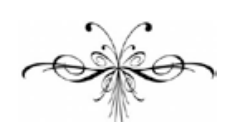

\section{BERTHOLD ZILLY}

Simone Homem de Mello (Tradutora)

Resumo: Originariamente publicado como posfácio à tradução de Memorial de Aires em alemão (Tagebuch des Abschieds. Berlim: Friedenauer Presse, 2009), este artigo contextualiza a obra de Machado de Assis, em especial seu último romance, no ambiente sociopolítico brasileiro do século XIX. Além de abordar aspectos biográficos e históricos relevantes para a compreensão da obra e de traçar um histórico de sua recepção, o artigo aponta questões tradutórias e paralelos interculturais, funcionando como um importante paratexto da tradução alemã.

Palavras-chave: Machado de Assis; Memorial de Aires; tradução alemã.
Abstract: Originally published as an afterword to the German translation of Memorial de Aires, entitled Tagebuch des Abschieds (Berlin: Friedenauer Presse, 2009), the present article contextualizes the literary production of Machado de Assis, especially his last novel, in the Brazilian socio-political environment of the 19th century. Besides approaching biographical and historical aspects which are relevant to the understanding of the novel, it discusses translation questions and intercultural parallels, working as an important paratext to the German translation.

Keywords: Machado de Assis; Memorial de Aires; German translation. 
E ste ensaio foi escrito como posfácio à tradução de Memorial de Aires, de Machado de Assis, para o alemão, por Berthold Zilly, intitulada Tagebuch des Abschieds [Diário da despedida] e publicada em 2009 pela Friedenauer Presse, em Berlim, numa edição de notável cuidado gráfico. As notas ao ensaio aqui traduzido foram formuladas em diálogo com o autor. As discrepâncias entre original e tradução decorrem de escolhas do próprio autor durante o processo de revisão do texto.

\section{EIN NOSTALGISCHER SPÖTTER}

»Zum Schluß stirbt ein Alter und zwei Junge heiraten sich das ist so ziemlich alles, was auf 500 Seiten geschieht. Von Verwicklungen und Lösungen, von Herzenskonflikten oder Konflikten überhaupt, von Spannungen und Überraschungen findet sich nichts. [...] Alles Plauderei, Dialog, in dem sich die Charaktere geben, mit und in ihnen die Geschichte. Natürlich halte ich dies nicht nur für die richtige, sondern sogar die gebotene Art, einen Zeitroman zu schreiben«.

Was Theodor Fontane im Todesjahr 1898 über seinen letzten, im Jahr zuvor erschienenen Roman, Der Stechlin, geschrieben hat, gilt - bei grundlegenden Unterschieden des Umfangs, der Milieuschilderung, des Aufbaus und Stils - in vieler Hinsicht auch für Tagebuch des Abschieds, den 1908 erschienenen letzten Roman des Brasilianers Joaquim Machado de Assis (1839-1908). Der Tod bildet hier von Anbeginn einen Kontrapunkt mit dem Leben und der Liebe, so daß sich alles Geschehen zwischen Diesseits und Jenseits abspielt, zumal der Ich-Erzähler, der Diplomat im Ruhestand Aires, vom Rande des Lebens her

\section{UM GALHOFEIRO NOSTÁLGICO}

"No final, morre um velho e dois jovens se casam - isso é mais ou menos tudo o que acontece nessas 500 páginas. Não há nada de enredamentos e desenlaces, nada de conflitos sentimentais ou de quaisquer outros conflitos, nada de tensões e surpresas. Tudo apenas conversa, um diálogo no qual os personagens se revelam, e com eles, dentro deles, a história. Naturalmente, considero esse o modo não apenas correto, mas também conveniente de se escrever um romance de época."

O que Theodor Fontane ${ }^{1}$ escreveu em 1898, ano de sua morte, sobre seu último romance, Der Stechlin [O Stechlin], publicado no ano anterior, sob muitos aspectos também se aplica - resguardadas diferenças fundamentais de extensão, descrição de ambiente, construção e estilo - a Memorial de Aires, o último romance do autor brasileiro Joaquim Machado de Assis (1839-1908), publicado em 1908. Aqui, mais ainda do que no romance de Fontane, a morte representa, desde o início, um contraponto à vida e ao amor, de modo que tudo se passa entre este mundo e o além, mesmo porque o narrador em primeira pessoa, o diplomata 
schreibt. Er notiert nicht nur zwanglose Gespräche, Briefe und Reflexionen, unter weitgehendem Verzicht auf eine äußere Handlung, sondern betreibt das Tagebuchschreiben überhaupt als eine Plauderei mit sich selbst. Auch dies ist ein Roman mit autobiographischen Bezügen, in denen der Autor vom Leben und von einer Epoche, der Gesellschaft der Kaiserzeit mit ihren hierarchisch-ständischen Zügen, Abschied nimmt und seine Figuren Abschied nehmen lässt.

Im Vordergrund stehen private, scheinbar banale Vorgänge und Episoden, deren lautlose, untergründige Dramatik sich nur bei genauem Lesen erschließt. Hin und wieder meldet sich im Hintergrund die große Geschichte, die nationale wie die internationale, mit ihren Gewalttaten, Kriegen und Revolutionen zu Wort. Des scheinbar schwerelosen Plaudertones ungeachtet werden grundlegende Fragen des Menschseins verhandelt, gute oder böse Anlagen der menschlichen Natur, Regeln eines zivilisierten Miteinanders, die charakter- und gesellschaftsbildende Rolle von Kunst und Literatur, die Beziehungen zwischen den Geschlechtern, den Generationen, den Ständen und Klassen, Kinderlosigkeit und nicht zuletzt Perspektiven und Schwierigkeiten des Alterns. Mehr noch als der Major Stechlin liebt der brasilianische Tagebuchschreiber das, was Fontane »Eulenspiegeleien« nennt: Wortwitz, Paradoxe, Infragestellung von allem und jedem, eine scheinbare Standpunktlosigkeit, womit der ironisch-nostalgische Agnostiker seine Gesprächspartner - und seine Leser, wiewohl er angeblich nur für sich selbst schreibt foppt. "Unanfechtbare Wahrheiten gibt es überhaupt nicht, und wenn es welche gibt, so sind sie langweilig « - dieser Ausspruch des märkischen Junkers könnte auch vom Geheimrat Aires stammen. aposentado Aires, escreve a partir da fase final de sua vida. Ele não só registra conversas casuais, cartas e reflexões, dispensando em grande parte um enredo externo mais palpável, como - no fundo - pratica a redação do diário como uma conversação consigo mesmo. Este também é um romance com referências autobiográficas, no qual o autor se despede e deixa seus personagens se despedirem da vida e de uma época, da sociedade do Império e de sua estratificação hierárquico-estamental. ${ }^{2}$

Em primeiro plano se passam acontecimentos e episódios privados, aparentemente banais, cuja discreta e subjacente dramaticidade só se desvenda em uma leitura mais detida. No pano de fundo, sempre volta a se manifestar a grande História, a nacional e a internacional, com seus atos de violência, guerras e revoluções. Não obstante o tom conversacional aparentemente desprovido de gravidade, enfocam-se questões fundamentais da existência, boas e más predisposições da natureza humana, regras de uma convivência civilizada, o papel formador da arte e da literatura para o caráter dos indivíduos e da sociedade, as relações entre os sexos, entre as gerações, os estamentos e classes sociais, a ausência de filhos e também as perspectivas e dificuldades do envelhecimento. Mais até que o major Stechlin, o brasileiro cultivador de seus diários ama o que Fontane denomina Eulenspiegeleien: ${ }^{3}$ engenhos de linguagem e paradoxos, o questionamento de tudo e todos e uma aparente falta de posicionamento, com os quais este irônico-nostálgico narrador agnóstico zomba de seus interlocutores - e de seus leitores, apesar de ele pretensamente só escrever para si mesmo. "Não existem verdades inquestionáveis, e se existirem, devem ser entediantes": esse dito do Junker ${ }^{4}$ brandenburguês poderia muito bem provir do Conselheiro Aires. 
Joaquim Maria Machado de Assis war einer der erstaunlichsten Autodidakten, von denen man je gehört hat. Er wurde 1839 in einem nordwestlich der Stadtmitte gelegenen, damals noch ein wenig ländlich anmutenden Viertel von Rio de Janeiro geboren, als Sohn eines Anstreichers mit afrikanischen Wurzeln und einer Wäscherin aus Portugal, die starb, als er zehn Jahre alt war. Über seine Kindheit ist wenig bekannt. Nichts ließ ahnen, daß er seiner proletarischen Herkunft, seiner dunklen Hautfarbe, seiner Halbwaisenschaft, seiner fragilen Gesundheit, seinem rudimentären Schulbesuch zum Trotz sich zum bedeutendsten lateinamerikanischen Schriftsteller seiner Zeit emporschreiben würde. Rio de Janeiro, um 1880 eine weltoffene Handelsstadt von 500000 Einwohnern, die er ebenso wenig verlassen hat wie Kant das viel kleinere Königsberg, war ihm Voraussetzung seines Schreibens und Habitat seiner Gestalten.

Im damaligen Brasilien gab es Konventionen, welche die abgrundtiefen gesellschaftlichen Unterschiede in Einzelfällen zu überbrücken vermochten: Patenschaft und Gönnerschaft. Die Besitzerin des Anwesens auf dem Morro do Livramento, bei der Machados Eltern eine Art Hintersassen waren, die reiche und gebildete Witwe eines Senators, nahm den kleinen Joaquim Maria für eine Weile unter ihre Fittiche, und auch später fand der vielseitig begabte und überaus fleißige Junge einflußreiche Förderer, darunter den Direktor der Staatsdruckerei und Verfasser des ersten brasilianischen Schelmenromans, Manuel Antônio de Almeida. Der kleine Machado war vom entschiedenen Willen zum sozialen Aufstieg erfüllt, ein häufiges Motiv in seinen späteren Erzählungen und Romanen. Er brachte es vom Bonbonverkäufer und Ladengehilfen zum Buchhalter, Setzer und Korrektor, er frequentierte Buchhandlungen und literarische Cafés und machte
Joaquim Maria Machado de Assis foi um dos mais notáveis autodidatas de que jamais se teve notícia. Nasceu em 1839, num bairro ao noroeste do centro de Rio de Janeiro e com um aspecto ainda um pouco rural na época, como filho de um pintor de paredes de origem africana e uma lavadeira portuguesa, falecida quando ele tinha dez anos de idade. Sabe-se pouco de sua infância. Nada indicava que ele - apesar de sua origem proletária, da pele escura, apesar da meia orfandade, da saúde frágil, da rudimentar educação escolar - viria a se tornar o mais significativo escritor latino-americano de sua época.

O Rio de Janeiro, que em 1880 era uma cidade mercantil cosmopolita de quinhentos mil habitantes e da qual Machado de Assis saiu tão pouco quanto Kant da bem menor Königsberg, era o fundamento de sua atividade literária e o habitat de seus personagens.

No Brasil daquela época, havia convenções que, em casos isolados, chegavam a atenuar as profundas diferenças sociais: o apadrinhamento e o patrocínio. A rica e ilustrada viúva de um senador do Império, abastada proprietária de uma chácara no Morro do Livramento, de quem os pais de Machado eram agregados, manteve o pequeno Joaquim Maria por um tempo sob sua proteção. Posteriormente, o jovem versátil e extremamente aplicado encontrou outros influentes protetores, entre os quais o diretor da Tipografia Nacional e autor do primeiro romance malandro no Brasil, Manuel Antônio de Almeida. O pequeno Machado estava firmemente determinado a ascender socialmente, um motivo recorrente nos contos e romances que viria a escrever depois. Inicialmente vendedor de doces e auxiliar de loja, ele chegou a se tornar contador, tipógrafo e revisor; frequentou livrarias e cafés literários, conquistando ainda jovem um nome 
sich schon in jungen Jahren, als Poet, Journalist, Übersetzer, Rezensent, Essayist, Theaterkritiker, Theaterautor und schließlich auch als Prosaerzähler einen Namen. Bereits 1855, im Alter von kaum 16 Jahren, hatte er sein erstes, romantisch empfundenes Gedicht, A Palmeira, veröffentlicht, worin das lyrische Ich seinen Liebesschmerz einer Palme klagt. So gewann er nach und nach Zutritt zur Republik der Gebildeten seines Landes, der er sein Leben lang angehören und deren Spiritus Rector er eines Tages werden sollte. Bald standen ihm die bedeutendsten Blätter offen, und allmählich brachte er es zu Wohlstand und Ansehen. Zeitgenossen beschreiben ihn als überaus höflich und ein wenig schüchtern, dennoch gesellig und freundlich, obgleich nicht sehr beredsam, vielleicht eine Folge der Epilepsie.

Daneben war Machado Regierungsbeamter und brachte es schließlich zu einem Rang, der etwa dem eines Ministerialdirektors entspricht. Seinen Dienst versah er mit außerordentlicher Tüchtigkeit und Gewissenhaftigkeit. »Ofício«Beruf, Dienst, Auftrag, Amt, Verpflichtung - ist gewiß nicht zufällig eines der Schlüsselwörter im Tagebuch des Abschieds; mehr oder weniger ironisch verwendet, deutet es dennoch auf einen Grundzug im Charakter des Autors.

Neben seinen drei höchst erfolgreichen Karrieren - als Journalist, Schriftsteller und Beamter - war er ehrenamtlich tätig, so als Gründungsmitglied und erster, lebenslanger Präsident der Academia Brasileira de Letras, der Brasilianischen Akademie für Literatur, die, 1897 nach dem Vorbild der Académie Française ins Leben gerufen, es sich zur Aufgabe machte, die brasilianische Literatur, die portugiesische Sprache und ganz allgemein die Nationalkultur zu pflegen und zu fördern. como poeta, jornalista, tradutor, resenhista, ensaísta, crítico de teatro, dramaturgo e, por fim, ficcionista.

Em 1855, na idade de 15 anos, ele publicou seu primeiro poema, ainda de inspiração romântica, "A palmeira", no qual o eu lírico lamenta para uma palmeira suas dores de amor. Pouco a pouco, ele conquistou acesso à república dos letrados de seu país, à qual pertenceria pelo resto de sua vida e da qual um dia viria a ser o spiritus rector. Logo os principais jornais lhe abririam as portas, o que gradativamente lhe proporcionou bem-estar e reputação. Seus contemporâneos o descreviam como altamente cortês e um pouco tímido, mesmo assim sociável e gentil, embora pouco eloquente, talvez uma consequência de sua epilepsia.

Paralelamente, Machado era funcionário do governo e chegou à posição de primeiro-oficial da Secretaria de Estado do Ministério da Agricultura. Exercia seu ofício com extraordinária competência e responsabilidade. Certamente não é à toa que "ofício" é uma das palavras-chave em Memorial de Aires; utilizada de forma mais ou menos irônica, ela remete, contudo, a um traço básico do caráter do autor. Além de suas três carreiras altamente bem-sucedidas como jornalista, escritor e funcionário público -, ele também exerceu funções honorárias, por exemplo como membro fundador e primeiro presidente da Academia Brasileira de Letras, criada em 1897 segundo o modelo da Académie Française, com a função de cultivar e incentivar a literatura brasileira, a língua portuguesa e, de modo geral, a cultura nacional. 
Als er 1869 Carolina de Novais, eine Portugiesin, heiratet, ist er bereits, obwohl er noch keines seiner heute meistgeschätzten Werke veröffentlicht hat, einer der erfolgreichsten Journalisten und Literaten seines Landes, dessen Name in einem Atemzug mit dem des berühmten José de Alencar genannt zu werden beginnt, eines Hauptvertreters des romantischen Romans. Das Ehepaar wohnt 1878-84 in der Rua do Catete, derselben Straße, in der sich später der Geheimrat Aires niederlassen wird; 1884 beziehen die beiden ihr endgültiges Domizil, ein zweistöckiges Häuschen mit Garten in Cosme Velho, einem gutbürgerlichen Viertel am Fuße des Corcovado-Felsens, oberhalb von Laranjeiras. Machado, von Freunden und Bewunderern fortan »der Zauberer von Cosme Velho« genannt, gehört nun endgültig zur gehobenen Gesellschaft. Mit Carolina führt er über dreißig Jahre lang eine glückliche, wenn auch kinderlose Ehe, wohl das Modell für die des Ehepaars Aguiar in seinem letzten Roman. Als seine Frau im Jahre 1904 stirbt, ist er - ähnlich wie Fidélia und Rita nach ihrer Verwitwung - von Schmerz und Wehmut erfüllt. Jeden Sonntag pilgert er zum Friedhof São João Batista und legt ihr Blumen aufs Grab, eine Gepflogenheit, auf die er in seinem ergreifenden Sonett Carolina anspielt. Sein Lebenswille ist geschwächt und er ahnt, daß er nicht mehr lange zu leben hat. Von diversen Krankheiten geplagt, schreibt er an seinem letzten Roman, Tagebuch des Abschieds, der zwei Monate vor seinem Tode erscheint und von der Kritik seines Landes überaus freundlich aufgenommen wird.

Als Machado stirbt, am 29. September 1908, trauert die Nation. Er wird in der Academia Brasileira de Letras aufgebahrt, und Tausende folgen am nächsten Tag dem Trauerzug nach Botafogo, wo er neben seiner Frau bestattet wird. Kirchlichen Sterbesegen hat er nicht gewollt; kein Priester hat ihn begleitet.
Em 1869, quando ele se casou com a portuguesa Carolina de Novais, embora ainda não tivesse publicado nenhuma de suas obras mais apreciadas hoje, já era um dos mais bem-sucedidos jornalistas e literatos de seu país, cujo nome começava a ser mencionado quase em pé de igualdade com o famoso José de Alencar, um dos principais representantes do romance romântico. O casal morou de 1878 a 1884 na Rua do Catete, a mesma onde viria a se estabelecer mais tarde o Conselheiro Aires. Em 1884, o casal Machado fixou domicílio numa casinha de dois andares com jardim, no Cosme Velho, um bairro burguês aos pés do Corcovado, no alto de Laranjeiras. Machado, denominado por amigos e admiradores de "Bruxo do Cosme Velho", passava então a pertencer definitivamente ao establishment. Com Carolina ele viveu durante mais de trinta anos, em um matrimônio feliz, que no entanto - não lhe trouxe filhos, algo que serviria de modelo para o casal Aguiar no último romance de Machado. Quando sua esposa faleceu, em 1904, ele foi abalado por grande dor e saudade, o mesmo que aconteceria com Fidélia e Rita em sua viuvez. Todo domingo ele peregrinava ao cemitério São João Batista, levando flores ao túmulo de sua esposa, um hábito ao qual ele alude em seu comovente soneto "Carolina". Sentindo-se atingido em sua vontade de viver, ele pressentia que não viveria muito mais tempo. Afetado por diversas doenças, escreveu seu último romance, Memorial de Aires, que viria a ser publicado dois meses antes de sua morte, sendo recebido favoravelmente pela crítica de seu país.

Quando Machado morreu, em 29 de setembro de 1908, a nação ficou de luto. Ele foi velado na Academia Brasileira de Letras e, no dia seguinte, milhares de pessoas acompanharam o cortejo fúnebre até o cemitério São João Batista, no Botafogo, onde ele foi sepultado ao lado de sua mulher. Ele havia dispensado 
Außerhalb Brasiliens brauchte es einige Zeit, bis er ein größeres Publikum fand, ab der Jahrhundertwende in Uruguay und Argentinien, ab den vierziger Jahren des 20. Jahrhunderts in Europa und den USA, ab den fünfziger Jahren auch im deutschen Sprachraum, wo ihn unter anderen der Germanist und Komparatist Wolfgang Kayser bekannt gemacht und übersetzt hat. Spätestens seit der Würdigung durch Jorge Luis Borges, Harold Bloom und Susan Sontag hat sich unter Literaturliebhabern herumgesprochen, daß Machado de Assis einer der Großen der Weltliteratur ist.

Im Alter von 25 Jahren begann Machado regelmäßig kürzere und längere, zum Teil novellenartige Geschichten zu schreiben, in denen er sich vom romantischen Geschmack immer weiter entfernte; die in seiner Reifezeit geschriebenen werden längst den Erzählungen von Tschechow oder Pirandello an die Seite gestellt. Auch seine crônicas, Zeitungsglossen, humorvolle oder satirische Prosaminiaturen über Tagesnachrichten und Alltagsepisoden, die er früh zu schreiben begann, oft unter Pseudonym, um mehr kritische Bewegungsfreiheit zu haben, waren von großem Einfluß auf seine Poetik als Erzähler, die im Unscheinbaren, Gewöhnlichen und Banalen das Seltsame, Komische und zugleich Erhellende hervorhebt.

Von 1872 bis zu seinem Tode schrieb er neun Romane, von denen die letzten fünf als Meisterwerke gelten: Memórias póstumas de Brás Cubas (Die nachträglichen Memoiren des Brás Cubas; 1880), Quincas Borba (1892), Dom Casmurro (1900), Esaú e Jacó (»Esau und Jakob«; 1904) sowie Memorial de Aires (Tagebuch des Abschieds; 1908). Literaturkritik und Literaturwissenschaft haben sich vor allem mit den drei a extrema-unção; e nenhum sacerdote o acompanhou.

Fora do Brasil, demorou um certo tempo até Machado de Assis conquistar um público mais amplo: a partir da virada do século XIX para o XX no Uruguai e na Argentina, a partir dos anos 1940 na Europa e nos Estados Unidos, a partir da década de 1950 nos países de língua alemã, nos quais ele foi traduzido e propagado - entre outros - por Wolfgang Kayser, especialista em Filologia Germânica e Literatura Comparada. O mais tardar desde seu reconhecimento por Jorge Luis Borges, Harold Bloom e Susan Sontag, os círculos literários internacionais passaram a considerálo um dos grandes nomes da literatura universal.

Na idade de 25 anos, Machado começou a escrever regularmente histórias mais breves ou mais longas, em parte com traços de novela, nas quais se distanciaria cada vez mais do gosto romântico. Os contos escritos em sua maturidade há muito já são equiparados aos de Tchekhov ou Pirandello. Suas crônicas, miniaturas em prosa humorística ou satírica sobre notícias do dia ou episódios cotidianos, por ele escritas ao longo de toda a sua vida - muitas vezes com pseudônimo, o que lhe assegurava uma margem mais ampla de intervenção crítica -, exerceram grande influência sobre sua poética como ficcionista, poética esta que destaca, em meio àquilo que parece insignificante, comum e banal, elementos estranhos, cômicos e ao mesmo tempo elucidativos.

De 1872 até sua morte, ele escreveu nove romances, dos quais os últimos cinco são considerados obras-primas: Memórias póstumas de Brás Cubas (1880), Quincas Borba (1892), Dom Casmurro (1900), Esaú e Jacó (1904), bem como Memorial de Aires (1908). A crítica e a teoria literárias se dedicaram mais aos três primeiramente mencionados, os únicos traduzidos até agora para o alemão, enquanto os dois últimos encontraram durante 
erstgenannten beschäftigt, die auch bislang als einzige ins Deutsche übersetzt waren, während man sich mit den beiden Alterswerken lange Zeit schwer tat, vielleicht, weil sie sich von den gängigen Vorstellungen, die man mit der Romanform verbindet, am weitesten entfernen. In den letzten Jahrzehnten sind beide Werke jedoch stärker ins Blickfeld des Leserinteresses und der Forschung gerückt und in mehrere Sprachen übersetzt worden.

Schon die vorherigen Romane hatten bei ihrem Erscheinen eine gewisse Ratlosigkeit hinterlassen. Spätestens seit dem Tod des großen Alencar (1877) ergab sich das Paradox, daß die meisten Kritiker Machado de Assis für den bedeutendsten Schriftsteller ihres Landes hielten, dies aber - überspitzt gesagt - nicht recht begründen konnten. Es fiel ihnen schwer, die gefühlte literarische Qualität seiner Erzählungen und vor allem seiner Romane auf den Begriff zu bringen, so daß manch einer schon bei den Nachträglichen Memoiren des Brás Cubas und erst recht beim Tagebuch des Abschieds Zweifel äußerte, ob dies denn überhaupt Romane seien. Der reife Machado ließ sich keiner Strömung zuordnen, war offenbar niemandes Schüler und bildete auch im Alter keine Schule. Man vermißte, je nachdem, ob man sich eher an Chateaubriand und Hugo oder an Zola und dem Portugiesen Eça de Queiroz orientierte, starke Gefühle, Schwung und Phantasie, eine ereignisreiche Intrige, eine fesselnde Liebeshandlung, ausgeprägte Charaktere, Darstellung von Sitten und Gebräuchen, Lokalkolorit, eine ausführliche Milieubeschreibung, einen deutlichen Erzählerstandpunkt oder eine erkennbare Botschaft, und man störte sich an der Dunkelheit mancher Passagen, an der Zufälligkeit der Vorgänge, an der Exzentrik des Erzählers, am weltanschaulichen Skeptizismus und Pessimismus. Andererseits bewunderte man Machados stilistische muito tempo maior dificuldade na recepção, talvez por se distanciarem mais daquilo que usualmente se espera da forma do romance. No entanto, nas últimas décadas, ambas as obras passaram a atrair mais o interesse dos leitores e pesquisadores, tendo sido traduzidas para diversas línguas.

Os romances anteriores já haviam causado certa perplexidade. O mais tardar desde a morte do grande Alencar (1877), ficou evidente um paradoxo: a maioria dos críticos considerava Machado de Assis o escritor mais significativo de seu país, mesmo que - para formular a questão de forma extremada - não soubessem justificar muito bem esse julgamento. Tinham dificuldade de conceitualizar a qualidade literária que percebiam em seus contos e, sobretudo, em seus romances, sendo que um ou outro chegou a duvidar de que Memórias póstumas de Brás Cubas e sobretudo Memorial de Aires fossem romances de fato.

O Machado da maturidade não se deixava enquadrar em nenhuma corrente literária, não foi discípulo de ninguém e também não formou escola, nem mesmo em sua fase tardia. Caso o leitor fosse norteado por Chateaubriand e Hugo ou por Zola e por Eça de Queiroz, ele sentiria falta de fortes emoções, brio e fantasia, de um enredo repleto de acontecimentos, de uma cativante história de amor, de personagens mais bem perfilados, da representação de hábitos e costumes, de cor local, de uma descrição minuciosa do ambiente, de um ponto de vista narrativo nítido ou de uma mensagem facilmente reconhecível, além de se sentir incomodado pela obscuridade de certos trechos, pela casualidade dos episódios narrados, pela excentricidade do narrador, pela visão de mundo cética e pessimista. Por outro lado, admirava-se a elegância 
Eleganz, seinen subtilen Witz, seine genaue psychologische Beobachtung, seine scharfsinnige philosophische Reflexion, seine stupende Gelehrsamkeit, seinen kosmopolitischen Universalismus. Man ahnte das Neue und Große in seinem Werk, konnte es aber nicht recht fassen.

Eine zunächst sehr kleine und nach seinem Tode wachsende Schar von Kritikern, wie auch Machado selbst, sah seine Besonderheit in seinem andeutungsreichen Stil, seiner Kunst der Andeutung und Anspielung, in seiner Verwendung der Ironie als Verfahren, aber auch als Erkenntnismittel. Das Wesentliche, so spürte man, waren nicht mehr Stoff und Handlung, nicht mehr das Erzählte und Beschriebene, sondern die suggestive, vexierbildhafte Form des Erzählens und Beschreibens, über die außerdem der Erzähler selbst des öfteren metaliterarisch reflektiert. Das Eigentliche des Romans liegt in der »Mache«, wie Fontane von seinem Stechlin gesagt hat, in der subtilen Kunst der Doppelbödigkeiten und Anspielungen, in der fast musikalischen Sorgfalt der Exposition und Durchführung von Themen und Motiven, in der Launenhaftigkeit des Erzählers, der skeptischen Weltsicht, dem systematischen Zweifel, den er von den Aufklärern geerbt hat, vor allem von denen englischer Provenienz.

Die Leser, die einen Roman Machados aufschlagen, werden zwar einigermaßen unterhalten, erheitert und belehrt, aber auch verwirrt und in den Erwartungen, die sie an diese Gattung richten, düpiert; und wenn die vielen Leerstellen und Rätsel sie auffordern, am Text gewissermaßen mitzuschreiben und zum Mitautor zu werden, so war und ist das nicht jedermanns Sache. Der vielleicht differenzierteste Kritiker im damaligen Brasilien, José Veríssimo, schrieb 1892: »Herr Machado de Assis ist weder ein Romantiker noch ein Naturalist noch ein Nationalist, noch ein Realist, er läßt estilística de Machado, sua espirituosidade sutil, sua acurada observação psicológica, sua aguçada reflexão filosófica, sua estupenda erudição, seu universalismo cosmopolita. Era possível intuir a novidade e grandeza de sua obra, mas impossível designálas adequadamente.

Um grupo de críticos inicialmente bastante reduzido, mas gradativamente ampliado após a sua morte, reconhecia - como o próprio autor também - sua singularidade em sua arte da insinuação e da alusão, no uso virtuoso da ironia como recurso estilístico, mas também como método de conhecimento da realidade psicossocial. Dava para sentir que o essencial não era mais a matéria e o enredo, nem o narrado e o descrito, mas sim a forma sugestiva e cifrada de narrar e descrever por meio de imagens cambiantes como ilusões de ótica, sobre a qual o próprio narrador frequentemente fazia reflexões metaliterárias.

O que singulariza o romance é a "feitura", como dizia Fontane a respeito de seu Stechlin, ou seja, a sutil arte da ambiguidade, a acuidade quase musical da exposição e do desenvolvimento de temas e motivos, a aparente volubilidade do narrador, a visão de mundo cética, a dúvida sistemática que o autor herdara dos iluministas e satíricos.

Dessa forma, os leitores que começarem a ler um romance de Machado provavelmente se divertirão até certo ponto, alegrandose e talvez instruindo-se, mas também se sentirão inseguros e ludibriados em suas expectativas a respeito desse gênero literário; e se os inúmeros enigmas e elipses exigem que os leitores sejam de certa forma coautores do texto, sabe-se que isso não é necessariamente do agrado de todos. O crítico talvez mais refinado do Brasil naquela época, José Veríssimo, escreveu em 1892: "O Sr. Machado de Assis, não é nem um romântico, nem um 
sich unter keinen Begriff mit der Endung -ismus oder -ist subsumieren." Trotz der »ironischen und humoristischen Form« erkannte er in seinem Werk »ein ausgezeichnetes Bild unseres Lebens und unserer Sitten «, wirft ihm andererseits jedoch vor, er stehe "außerhalb des brasilianischen Lebens", ein gewisser Widerspruch, der nicht aufgelöst wird und der sich auch bei späteren Kritikern findet, so bei einem anderen großen Humoristen und Romancier Brasiliens, auch einem Nachkommen von Sklaven, Afonso Henriques de Lima Barreto. Mit beispielloser Neugier und Ausdauer las Machado sich in Themen, Motive und Techniken der Weltliteratur ein, ohne je den Blick von der eigenen Kultur und Gesellschaft abzuwenden. Prägend für seinen ironischen Stil und seine skeptische Weltsicht waren, neben vielen anderen, Lukian, Voltaire, Swift, Sterne, Xavier de Maistre, Garrett, Thackeray, Heine und Schopenhauer. Sein Sinn fürs Karikatureske und Skurrile erinnert gelegentlich an Gogol, den er kannte, und an Wilhelm Busch, den er offenbar nicht kannte.

Machado war nicht nur Gegenstand, sondern auch Subjekt der Kritik. Durch sein eindrucksvolles essayistisches und vor allem erzählerisches Werk hat er die brasilianische Literaturkritik und Leserschaft allmählich genötigt, traditionelle Gattungs- und Stilvorstellungen zu relativieren und sich Neuerungen zu öffnen. Bis zum heutigen Tage ist er gewissermaßen der literarische Erzieher seiner Landsleute.

Auch gelang ihm das Kunststück, die Gesellschaft seiner Zeit, vor allem ihre Eliten, satirisch bloßzustellen und von ihnen zugleich als repräsentativer, ja klassischer Nationalautor gefeiert zu werden. Das könnte verwundern, sind doch Handlung und Personal seiner Werke, bei Licht besehen, wenig erbaulich und naturalista, nem um nacionalista, nem um realista, nem entra em qualquer dessas classificações em 'ismo' ou 'ista"'.

Apesar da forma irônica e humorista, o crítico reconheceu na obra de Machado "um quadro excelente da nossa vida e dos nossos costumes", acusando-o - por outro lado - de se manter à parte da vida brasileira, uma contradição que não se dissipará e que se repetirá em críticos posteriores, como é o caso de outro grande humorista e romancista brasileiro, igualmente descendente de escravos, Afonso Henriques de Lima Barreto.

Com uma curiosidade e um fôlego sem precedentes, Machado mergulhou em temas, motivos e técnicas da literatura universal, sem jamais tirar os olhos de sua própria cultura e sociedade. Entre muitos autores que marcaram seu estilo irônico e sua visão de mundo cética estão Luciano, Voltaire, Swift, Sterne, Xavier de Maistre, Garrett, Thackeray, Heine e Schopenhauer. Seu gosto pelo caricatural e pelo bizarro ocasionalmente lembra Gogol, que ele conhecia, e Wilhelm Busch, que - ao que tudo indica - ele desconhecia.

Machado não foi apenas objeto, mas também sujeito da crítica. Por meio de sua impressionante obra ensaística e sobretudo narrativa, ele foi obrigando a crítica literária e o público leitor do Brasil a relativizar suas concepções tradicionais de gênero literário e de estilo e a se abrir para inovações. Até hoje ele não deixou de ser o educador literário de seus conterrâneos.

Além disso, ele conseguiu a proeza de desmascarar satiricamente a sociedade de sua época, sobretudo as elites, tendo sido - ao mesmo tempo - celebrado por elas como autor nacional representativo, até clássico. Isso poderá causar espanto, considerando que os enredos e os personagens de suas obras, 
noch weniger staatstragend. Ab den siebziger Jahren werden seine Figuren zunehmend vom individuellen Wunsch nach Aufstieg, Reichtum, Macht, Status und Lust getrieben, und wo sie sich auf Tugenden, Werte und Grundsätze berufen, verstellen sie sich meistens, ja, die Verstellung, auch die vor sich selbst, ist geradezu eine Kulturtechnik seines fiktionalen Kosmos und ein Markenzeichen seiner Charaktere. Wenn er über die höheren Stände mit besonderer Bissigkeit spottet, so hütet er sich doch, die unteren zu idealisieren. In den Nachträglichen Memoiren des Brás Cubas führt er einen ehemaligen Sklaven vor, der einst mißhandelt wurde und nun, zum Sklavenhalter geworden, seinerseits Sklaven mißhandelt, ein Beispiel für die enttäuschende Erkenntnis, daß Unterdrücktwerden nicht notwendigerweise besser macht. Überwindung der Eigenliebe - Ehrlichkeit, Güte, Zuneigung findet sich allerdings, sofern überhaupt, eher bei den kleinen Leuten, vor allem aber bei Naiven und bei Verlierern aller gesellschaftlichen Gruppen, worin man eine resignative Haltung zu sozialdarwinistischen Verhaltensweisen sehen mag, obschon er diese zugleich parodiert.

Tagebuch des Abschieds nahm lange in der Kritik eine Sonderstellung ein und galt fast als ein Solitär der Versöhnlichkeit in Machados Gesamtwerk. Hier fand man einen lyrischen Ton, ein friedvolles Welt- und Menschenbild, herzliches Einvernehmen, langjähriges Eheglück, idyllische Szenen der Freundschaft und Geselligkeit, wozu die mehrfache Nennung des Bukolikers Theokrit zu passen scheint. Den Generalverdacht der Selbstsucht, Launenhaftigkeit und Täuschung, der fast alle Figuren und vistos de perto, são pouco edificantes e muito pouco afirmativos da ordem estatal.

A partir dos anos 1870, os personagens de Machado passam a ser crescentemente movidos por um desígnio individual de ascensão, riqueza, poder, status e prazer, e quando invocam virtudes, valores e princípios, geralmente é porque estão dissimulando; afinal, a dissimulação, inclusive em relação a si mesmo, representa uma verdadeira técnica cultural em seu cosmos ficcional e uma marca registrada de seus personagens. Se, por um lado, ridiculariza os estamentos superiores da sociedade com notável mordacidade, por outro, abstém-se de idealizar os inferiores. Em uma cena de Memórias póstumas de Brás Cubas, Machado apresenta um antigo escravo que outrora foi maltratado e que agora, tendo-se tornado senhor, passa a maltratar seus próprios escravos - um exemplo da decepcionante constatação de que a repressão não necessariamente melhora o caráter do reprimido. A superação do egocentrismo - por meio de honestidade, bondade, afeto - se manifesta, quando muito, entre as pessoas mais humildes, sobretudo nos ingênuos e nos perdedores de todos os grupos sociais, algo que faz supor uma certa resignação às formas de comportamento social-darwinistas, ao mesmo tempo parodiadas pelo autor.

Durante muito tempo, Memorial de Aires ocupou um lugar especial na crítica, sendo considerado praticamente um exemplo ímpar de conciliação em toda a obra de Machado. Nesse romance se reconheciam um tom lírico, uma imagem pacífica do mundo e do ser humano, uma harmonia cordial, uma longeva felicidade matrimonial, cenas idílicas de amizade e companheirismo, algo que parece combinar com a reiterada menção do poeta bucólico Teócrito. A suspeita generalizada de egoísmo, inconstância e 
Erzähler der vorherigen Romane trifft, habe Machado nunmehr überwunden. Und tatsächlich scheinen solche unerfreulichen Charakterzüge hier gemildert oder gar ersetzt durch Taktgefühl, Warmherzigkeit und Liebe - Bausteine einer privaten Utopie, Vorschein von Glück.

In den letzten Jahrzehnten ist es zu einer differenzierteren Sicht des Romans gekommen, die den Abstand von Tagebuch des Abschieds zu den früheren Werken nicht ganz leugnet, aber deutlich schrumpfen läßt. Wendet man Wörter und Sätze mehrfach um, liest man zwischen den Zeilen, folgt man Nebenbedeutungen und Anspielungen, vergegenwärtigt man sich den Gehalt von Metaphern und Symbolen, nimmt man das Wort beim Wort, so wird klar, daß auch diesem Erzähler nicht recht zu trauen ist, ebenso wenig wie seinen Gesprächspartnern und Gewährsleuten, obwohl der Geheimrat Aires mit der Pingeligkeit eines Protokollanten notiert, wo und wann ihm eine Neuigkeit bekannt geworden oder ein Gedanke gekommen ist. Ob es aber um äußere Fakten oder Gedanken und Gefühle geht - fast alles bleibt Schein und Vermutung, auf nichts und niemand ist Verlaß.

In der Übersetzung tritt der Zweifel des Erzählers am Wahrheitsgehalt seiner Tagebucheinträge besonders deutlich zutage, da die deutsche Sprache in der indirekten Rede den Schreibenden, hier den Geheimrat Aires, nötigt, sich zu entscheiden, ob er den Wahrheitsanspruch seiner Informanten übernimmt oder implizit in Frage stellt. Da Aires an fast allen Aussagen, Gedanken, Gefühlen, seien es fremde, seien es eigene, seine Zweifel hat, wählt er für die indirekte Rede im Deutschen vorwiegend den Konjunktiv. ludíbrio que recai sobre quase todos os narradores e personagens dos romances anteriores teria sido superada por Machado. De fato, esses traços antipáticos de personalidade parecem atenuados nessa obra, ou até mesmo substituídos por tato, calor humano e amor, elementos estes de uma utopia privada, visão antecipada de felicidade.

No entanto, nas últimas décadas se chegou a uma visão mais sutil do romance, que não nega totalmente a distância de Memorial de Aires em relação às obras anteriores, mas a reduz substancialmente. Revirando-se algumas vezes as palavras e frases, lendo-se nas entrelinhas, atentando-se às insinuações e às diferentes conotações, percebendo-se o teor das metáforas e dos símbolos, levando as palavras ao pé da letra, pode-se perceber com clareza que este narrador também não é tão confiável assim, tão pouco quanto seus interlocutores e seus informantes, embora o Conselheiro Aires anote com a minúcia de um escrivão onde e quando obteve cada notícia ou teve algum pensamento. Sejam acontecimentos, ideias ou sentimentos, quase tudo permanece em suspenso, mantendo-se no nível da aparência e suposição: em última análise, não se pode confiar em nada e em ninguém.

Na tradução, a dúvida do narrador quanto à veracidade das anotações de seu diário fica mais nítida do que no original, pois a língua alemã obriga quem escreve em discurso indireto - no caso, o Conselheiro Aires -, a decidir se quer assumir a veracidade do que dizem seus informantes ou se prefere não assumi-la, colocando-a em questão, implicitamente. Como Aires tem suas dúvidas a respeito de quase todos os enunciados, pensamentos e sentimentos, sejam eles alheios ou próprios, ele escolhe - para o discurso indireto em alemão - predominantemente o modo verbal do subjuntivo. ${ }^{5}$ 
Einvernehmen und Freude beruhen zum Teil auf Irrtum und Täuschung, und wo diese aufbrechen, sind die Figuren - allem Wunsche nach Ausgleich, Maß und fast klassischer Dämpfung der Affekte und Konflikte zum Trotz - tief verunsichert, ja von Verzweiflung bedroht. Nur mit Witz und Humor und dem Lob der Entsagung, womit er sich vielleicht selbst belügt, kann Aires über den Schatten seiner Einsamkeit und seines erzwungenen Liebesverzichtes springen. Er ist viel weniger weise und abgeklärt als er sich einredet. Und die alten Eheleute Aguiar werden den halben Roman hindurch von der Sorge, ja Angst geplagt, sie könnten am Ende von ihren »Ersatzkindern« im Stich gelassen werden, ignorieren aber konsequent alle Hinweise darauf, daß es genau so kommen wird. Dabei sind hier, im Gegensatz zu früheren Werken des Autors, etliche Quellen von Konflikt und Täuschung, wie etwa soziale Asymmetrie unter Freunden und Liebenden, ausgespart. Andererseits können Irrtum und Täuschung auch im Dienste von Takt und Rücksicht stehen - ein implizites Plädoyer für eine Relativierung des kategorischen Imperativs. Vollkommene Ehrlichkeit und Selbstlosigkeit gibt es nicht, und gäbe es sie, würden sie das friedliche Zusammenleben stören oder zerstören.

Die idyllische Welt, unvollkommen und ohnehin nur Privilegierten zugänglich, ist auch strukturell gefährdet, durch Patriarchat, Sklaverei, Gewalt und Armut: Die unumschränkte Macht des pater familias drohte schon in der Vorgeschichte das Glück Fidélias und ihres Verlobten Noronha zu zerstören; auch hält der Ich-Erzähler es nicht für ausgeschlossen, daß der vom Kaiser zum Baron geadelte Kaffeepflanzer, eine ehemalige Stütze der Monarchie, seine eigene Tochter mit einer üblicherweise an Sklaven vollzogenen Strafe grausam mißhandeln könnte. Daß es
Harmonia e alegria se baseiam, parcialmente, em equívoco e ilusão; e onde quer que isso venha à tona, os personagens - apesar de todo o desejo de equilíbrio, de comedimento e de contenção, quase clássica, dos afetos e dos conflitos - são profundamente abalados em sua segurança e até ameaçados pelo desespero. Somente com agudeza, humor e com a apologia da abnegação, com os quais Aires talvez apenas minta para si mesmo, é que ele consegue dar a volta por cima de sua solidão e sua forçada desistência do amor. Ele é muito menos sábio e sereno do que tenta se convencer. E, ao longo de meio romance, o velho casal Aguiar é perseguido pela preocupação, pelo medo de que, no final das contas, possa ser abandonado por seus "filhos postiços", mas ignora sistematicamente todos os indícios de que é exatamente isso o que acontecerá. Ao contrário do que ocorre em obras anteriores do autor, aqui foram eliminadas algumas fontes de conflito e ilusão, por exemplo a assimetria social entre amigos e entre amantes. Por outro lado, o equívoco e a ilusão também podem estar a serviço do tato e da consideração - uma apologia implícita da relativização do imperativo categórico kantiano. Honestidade e altruísmo absolutos não existem e, se existissem, perturbariam ou destruiriam a convivência pacífica entre as pessoas.

O microcosmo idílico, questionável, e de qualquer forma acessível apenas aos privilegiados, é estruturalmente ameaçado pelo patriarcado, pela escravatura, pela violência e pela pobreza. O poder irrestrito do pater familias já ameaçava, nos momentos preliminares da trama, destruir a felicidade de Fidélia e de seu noivo Noronha; o narrador em primeira pessoa também não exclui a possibilidade, embora remota, de o barão do café, que recebeu do imperador esse título de nobreza e que representa um pilar da sociedade, cometer uma crueldade contra sua filha, por meio de 
bei Wahlen undemokratisch und gewalttätig zugeht, ist ebenso selbstverständlich wie Kinderarbeit in Stadt und Land.

Machados afrikanische Wurzeln waren ein wunder Punkt in seinem Leben oder vielmehr in der Gesellschaft seines Landes. Manche Kritiker hielten ihm vor, sich für die Sklaven, seine »Hautfarbenbrüder«, nicht genügend eingesetzt zu haben - ein unberechtigter Vorwurf, insbesondere dann, wenn man nicht nur sein belletristisches, sondern auch sein journalistisches Werk und seine Amtstätigkeit in Betracht zieht. Begonnen hatte Machado als das, was man seit Sartre einen engagierten Schriftsteller nennt; mit zwanzig Jahren schrieb er: »Ich bin so unsäglich monoman, daß ich die Kunst nicht um der Kunst willen betreibe, sondern so, wie Victor Hugo sie betreibt, als gesellschaftlichen, nationalen, menschlichen Auftrag.« Als junger Mann setzte er sich für die Menschenund Bürgerrechte ein, und seinen Gesinnungen ist er treu geblieben, auch wenn er später in seinen belletristischen Texten nicht mehr unmittelbar zu politischen Fragen Stellung nahm. Zur Abolition verhielt sich der Staatsbürger Machado de Assis weit entschiedener als sein literarisches Geschöpf, der Geheimrat Aires. Anders als dieser hat er an der Kundgebung zur Feier der Sklavenbefreiung am 13. Mai 1888 sehr wohl teilgenommen. Und als Beamter im Landwirtschaftsministerium hat er sich nachdrücklich dafür eingesetzt, daß das »Gesetz des freien Bauches« von 1871, das allen Kindern von Sklavinnen die Freiheit gab, im ländlichen Raum tatsächlich angewendet wurde.

Wie heikel andererseits die Stellung der freien Nichtweißen war, zeigt der Nachruf, den José Veríssimo auf seinen Freund Machado schrieb: Dieser Mulatte sei eigentlich ein Grieche des klassischen Zeitalters gewesen. Eine solche Formulierung uma punição usualmente aplicada em escravos. O fato de as eleições serem antidemocráticas e acabarem em violência é tão óbvio quanto o trabalho infantil na cidade e no campo.

As raízes africanas de Machado eram um ponto delicado em sua vida, ou melhor, na sociedade de seu país. Vários críticos o censuravam por ele não se empenhar o suficiente pelos escravos, seus "irmãos de cor" - uma censura injusta, sobretudo quando se considera não apenas sua obra ficcional, mas também seu trabalho jornalístico e sua atuação institucional. Machado começou como um tipo de escritor que, desde Sartre, se costuma designar "engajado". Aos vinte anos, ele escrevia: "Eu não tenho a arte pela arte, mas a arte como a toma Hugo, missão social, missão nacional e missão humana". Quando jovem, ele se engajava pelos direitos humanos e do cidadão, tendo se mantido fiel a esses ideais, mesmo que posteriormente, como escritor, não tenha se pronunciado diretamente sobre questões políticas. Em relação à Abolição, o cidadão Machado de Assis se comportou de forma bem mais decidida que sua criação literária, o Conselheiro Aires. Ao contrário deste, ele participou, sim, da manifestação para comemorar a abolição da escravatura, em 13 de maio de 1888. E como funcionário do Ministério da Agricultura, ele se empenhou enfaticamente pela implementação, na zona rural, da Lei do Ventre Livre, que fora promulgada em 1871 e libertou todos os filhos de escravas.

O quão frágil, por outro lado, era a posição de um cidadão livre não-branco se revela na homenagem que José Veríssimo escreveu sobre seu amigo Machado após sua morte: "Mulato, ele foi de fato um grego da melhor época." Uma formulação dessas 
bestätigte rassistische Vorurteile und stellte sie zugleich in Frage, indem sie auf die in Brasilien bestehende Möglichkeit anspielte, den "Makel« der nichtweißen Hautfarbe durch Bildungsanstrengung und Aneignung der europäischen Hochkultur - weitestgehend - zu kompensieren. Ebenso aufschlußreich und fragwürdig wie dieses Lob war der Einspruch eines anderen gemeinsamen Freundes, des Politikers und Schriftstellers Joaquim Nabuco: »Ich hätte Machado nicht einen Mulatten genannt, und ich meine, nichts hätte ihn mehr geschmerzt als diese Bezeichnung. [...] Für mich war Machado ein Weißer, und ich glaube, auch er hielt sich für einen solchen.« Wenn die Hochbegabten und Ehrgeizigen unter den Benachteiligten sich so verhielten, als wären sie nicht benachteiligt, konnten sie von der weißen - oder als weiß geltenden - Elite kooptiert werden, was im brasilianischen Kaiserreich (1822-89) wie auch in der Alten Republik (1889-1930) nicht selten geschah. Militanz aber war verpönt, und daran hielt sich Machado.

Wie zentral das Thema der Sklaverei im Tagebuch des Abschieds ist, lässt sich daraus ersehen, daß der Geheimrat Aires zwar viele Jahre lang tägliche Aufzeichnungen machte, der Herausgeber M. d. A., das Alter ego des Autors, jedoch diejenigen zur Veröffentlichung ausgewählt hat, die aus den Monaten vor und nach der Sklavenbefreiung stammten. Tatsächlich waren die Jahre 1888-89 in mehrfacher Hinsicht eine Epochenschwelle: die Sklavenbefreiung führte zur Republik, welche die Modernisierung vieler Lebensbereiche beschleunigte und das Stadtbild im Sinne der bewunderten europäischen Belle Epoque tiefgreifend veränderte, was Machado zum Teil mit nostalgischer Kritik begleitete: Sanierungs- und Urbanisierungsmaßnahmen, Beschleunigung des Verkehrs, Industrialisierung, Einwanderung, confirma os preconceitos racistas e, ao mesmo tempo, os coloca em questão, por aludir à possibilidade existente no Brasil de se compensar, em grande medida, a "mácula" da pele não-branca por meio do empenho em adquirir um bom nível de educação e por meio da assimilação da alta cultura europeia. Tão reveladora e questionável quanto este elogio foi a contestação de um outro amigo comum, o político e escritor Joaquim Nabuco: "Eu não teria chamado Machado de Assis de mulato e penso que nada lhe doeria mais do que essa síntese. O Machado para mim era um branco e creio que por tal se tomava."

Quando os talentosos e ambiciosos entre os desfavorecidos se comportavam como se não fossem desfavorecidos, eles podiam ser cooptados pela elite branca (ou considerada branca), o que não era incomum no Brasil durante o Império (1822-89) e durante a República Velha (1889-1930). A militância, todavia, era mal vista, e sabendo disso, Machado a evitava.

Um sinal de que o tema da escravidão ocupa uma posição central em Memorial de Aires é o fato de o Conselheiro Aires ter feito anotações diárias durante muitos anos, sendo que 0 organizador do diário, M.d.A., alter ego do autor, selecionou para publicação apenas aquelas relativas aos meses anteriores e posteriores à libertação dos escravos. De fato, os anos 1888-1889 constituem, por diversos motivos, um limiar entre épocas: a libertação dos escravos conduziu à República, que acelerou a modernização em muitos âmbitos da vida e modificou drasticamente a paisagem urbana de acordo com a admirada belle époque europeia, um processo que Machado aceitou com uma atitude crítica e nostálgica: medidas de saneamento e urbanização, aceleração do tráfego, industrialização, imigração, êxodo rural, 
Landflucht, Börsenspekulation, Proletarisierung, Entstehung der ersten Favelas. Nicht modernisiert im Sinne einer demokratischen, bürgerschaftlichen Nation wurde dagegen die politische Ordnung der Gesellschaft. So ist der Roman auch lesbar als Ausdruck der Enttäuschung über eine Republik, die in fast zwanzig Jahren nicht imstande und vielleicht nicht einmal willens war, die ehemaligen Sklaven zu integrieren, die Herrschaft der Kaffeeoligarchie und anderer Oligarchien zu erschüttern, die republikanischen Versprechen der Freiheit, der Gleichheit, des Rechtsstaats einer Verwirklichung entscheidend näher $\mathrm{zu}$ bringen. Brasilien erscheint, im Gegensatz zu dem idealisierten Bild, das Stefan Zweig etwa drei Jahrzehnte später entwerfen sollte, beinahe als ein Land ohne Zukunft.

Wenn auf einige der Romanfiguren neben vielem Licht auch einige moralische Schatten fallen, so hat dies auch mit der Widersprüchlichkeit und Unvollkommenheit der Abolition zu tun. Fidélia überlässt zwar großzügig ihre Ländereien den ehemaligen Sklaven, diese aber auch ihrem Schicksal und macht sich keinerlei Gedanken darüber, wie die so Beschenkten ohne Kapital, ohne Ausbildung, ohne Beratung erfolgreich wirtschaften könnten. Ihr übriges Vermögen, das nichts anderes ist als kapitalisiertes Sklavenblut, behält sie ganz selbstverständlich für sich. Natürlich wäre es völlig unrealistisch, von ihr eine weitere Unterstützung der Freigelassenen zu erwarten; schon die Schenkung des Landguts ist ein beinahe märchenhafter Zug. Fidélias Verhalten illustriert jedoch, daß selbst die Wohlmeinenden unter den Oberschichtsangehörigen ratlos und tatlos waren, was die Zukunft der mit so großem Pomp befreiten Sklaven betraf, die nun brasilianische Bürger waren, de facto aber Ausgeschlossene blieben. Ihr Weg ins städtische Subproletariat und in die Favelas especulação na bolsa de valores, proletarização, surgimento das primeiras favelas. A ordem política da sociedade, todavia, não se modernizou no sentido de constituir uma nação com cidadania e democracia. Dessa forma, este romance também pode ser lido como expressão da decepção com uma República que deixou transcorrer vinte anos, sem a capacidade e talvez nem sequer a vontade de integrar os antigos escravos, de abalar o domínio da oligarquia cafeeira e de outras oligarquias e de se aproximar de modo mais significativo do cumprimento das promessas republicanas de liberdade, de igualdade e de um Estado de direito. Ao contrário da imagem idealizada que Stefan Zweig viria a esboçar três décadas depois, o Brasil aqui parece quase um país sem futuro.

Se sobre alguns dos personagens deste romance recai, paralelamente a muita luz, uma certa sombra moral, isso também está ligado à contraditoriedade e à imperfeição da Abolição. Fidélia é generosa em deixar suas terras para os antigos escravos, mas também os relega ao seu destino, sem parar para pensar em como aqueles por ela agraciados poderão administrar a fazenda com êxito sem disporem de capital, instrução e orientação. O resto da fortuna, que não passa de sangue escravo capitalizado, ela o guarda para si mesma, com toda naturalidade. Evidentemente seria pouco realista esperar dela um apoio ainda maior aos libertados; a própria doação da fazenda já tem traços de um conto de fadas. Contudo, o comportamento de Fidélia ilustra que mesmo os bemintencionados entre os integrantes das classes altas estavam perplexos e paralisados diante do futuro dos escravos que haviam sido libertados com grande pompa e que eram, a partir de então, cidadãos brasileiros, permanecendo de facto excluídos. Sua trajetória rumo ao subproletariado urbano e às favelas era 
war unausweichlich.

Die Sklaverei ist die ökonomische Grundlage für die allseitige Bildung der jungen Witwe zu einer selbstbewußten, taktvollen, weltläufigen Frau, für ihre Entwicklung zur dreifachen Künstlerin - als Musikerin, Malerin, Briefautorin -, mit der man als Leser sogleich sympathisiert. Das gilt auch für ihre wichtigste, vom Erzähler immer wieder hervorgehobene, vielschillernde Eigenschaft: graça, also Anmut, Grazie, Reiz, Liebreiz, Charme, Wohlgefälligkeit, Eleganz, Stil, Geist, Witz, Esprit, Gunst, Gewogenheit, Wohlwollen, Dankbarkeit, auch Gnade. Anmut, ohne die ihre Schönheit keine Liebe einflößen könnte, offenbart sich in Rede, Gestik und Mimik, beim Musizieren, Malen und vor allem beim Gehen, beim Dahinschweben, denn Anmut ist, wie wir mit Schiller wissen, Schönheit in Bewegung. Das Künstlertum und Anmut ebendieser schöne Seele, in welcher Sinnlichkeit, Vernunft, Sittlichkeit, Schönheit eins geworden sind, sind, um ein Wort Adornos zu variieren, eine abgedungene Untat.

Andererseits: würde man auf Kunst und Kultur verzichten, würde die Untat, der sie sich verdankt, damit keineswegs verschwinden, es entstünde keinerlei Nutzen, vielmehr großer Schaden. Denn die Poesie ist, wie der Geheimrat Aires sagt, ein Medium der Anmut, aber sie ist auch, wie das ganze Werk Machados zeigt, eines der Wahrheitssuche. Ein Zweifler und Spötter war der Autor ja gerade deshalb, weil er ein - wenn auch wenig optimistischer - Wahrheitssucher war. Darauf weist der wohl bedeutendste brasilianische Lyriker des 20. Jahrhunderts in einem längeren Gedicht, dessen zwei letzte Strophen diese Beobachtungen abschließen mögen: inevitável.

A escravidão é a base econômica para a plena transformação da jovem viúva em uma mulher versada, dotada de autoconfiança e de tato, para o seu desenvolvimento como artista tríplice - música, pintora e missivista -, com a qual o leitor simpatiza imediatamente. Isso também vale para sua principal e mais evidente qualidade, constantemente destacada pelo narrador: a graça $^{6}$ - airosidade, garbo, encanto, atratividade, charme, agrado, elegância, estilo, agudeza, espirituosidade, favor, simpatia, benevolência, gratidão, serenidade, harmonia, bênção, perdão divino e outras qualidades.A graça, sem a qual sua beleza não poderia inspirar amor, se revela na fala, no gesto e na mímica, na prática da música e da pintura, mas sobretudo ao andar, ao flutuar pela rua, pois a graça - como sabemos de Schiller - é beleza em movimento. No entanto, a natureza de artista e a graça dessa bela alma, na qual se fundem sensualidade e juízo, beleza e moralidade, são - para variar um dito de Adorno - uma atrocidade regateada, ou seja, têm como origem, ou condição, um crime.

Por outro lado, se fôssemos abdicar da arte e da cultura, esse crime - ao qual ambas também devem sua existência - não desapareceria de forma alguma. Não haveria proveito algum, apenas um grande prejuízo. Afinal, a poesia - conforme afirma o Conselheiro Aires - é capaz de conferir graça aos costumes, mas também - segundo revela toda a obra de Machado - é capaz de ajudar as pessoas a indagar a si mesmas, a sociedade e as coisas últimas. Alguém que duvidava e galhofava de tudo tornou-se escritor justamente porque buscava a verdade, se bem que com pouco otimismo. É o que aponta Drummond, o grande poeta brasileiro do século XX, em um extenso poema cujas duas últimas estrofes podem concluir agora as presentes considerações: 


\section{An einen Zauberer, mit Liebe}

\section{$[\ldots]$}

Alle Friedhöfe gleichen sich

auf keinem läßt du dich nieder, vielmehr wo der Zweifel

den Marmor der Wahrheit befühlt, um zu entdecken

den notwendigen Spalt;

wo der Teufel mit dem Schicksal Dame spielt,

bist immer du da, Zauberer der Anspielung und des Spottes,

lösest so viele Rätsel in mir.

Ein ferner, sanfter Ton

dringt mitten unter Embryos und Ruinen,

ewige Totenfeiern und Hallelujas der Ewigkeit,

und läßt sogar dein pince-nez verrutschen.

Der Stallmeister Oblivion

klopft ans Tor und ruft zum Schauspiel,

aufgeführt zu ergötzen den Planeten Saturn.

Du drehst den Schlüssel,

wickelst dich in den Umhang,

und wie ein neuer Ariel, ohne weitere Antwort,

entschwindest du durchs Fenster, lösest dich auf in der Luft.

\section{“A um bruxo, com amor"}

[...]

Todos os cemitérios se parecem,

e não pousas em nenhum deles, mas onde a dúvida

apalpa o mármore da verdade, a descobrir

a fenda necessária;

onde o diabo joga dama com o destino,

estás sempre aí, bruxo alusivo e zombeteiro,

que resolves em mim tantos enigmas.

Um som remoto e brando

rompe em meio a embriões e ruínas,

eternas exéquias e aleluias eternas,

e chega ao despistamento de teu pencenê.

O estribeiro Oblivion

bate à porta e chama ao espetáculo

promovido para divertir o planeta Saturno.

Dás volta à chave,

envolves-te na capa,

e qual novo Ariel, sem mais resposta,

sais pela janela, dissolves-te no ar. 


\section{Notas}

${ }^{1}$ Theodor Fontane (1819-98) foi um dos grandes prosadores realistas de língua alemã no século XIX. Seus romances são um retrato crítico, entre humorístico, satírico e melancólico, da sociedade alemã da época, sendo os mais conhecidos Irrungen, Wirrungen (1888), Frau Jenny Treibel (1893), Effi Briest (1896), Der Stechlin (1897). Effi Briest, cuja versão cinematográfica, de Rainer Werner Fassbinder (1974), foi um êxito mundial, é comparado por muitos críticos com Madame Bovary, de Gustave Flaubert, O Primo Basílio, de Eça de Queiroz, Anna Karenina, de Liev Tolstói. Der Stechlin é o nome de um grande lago emoldurado por extensas florestas a $100 \mathrm{~km}$ ao norte de Berlim, que existe também na realidade extraliterária, sendo ao mesmo tempo, embora só na ficção de Fontane, o nome de uma família aristocrática da região e do seu chefe, o major reformado Dubslav von Stechlin.

${ }^{2}$ Aqui há uma alusão ao título do romance na tradução alemã. Por meio da escolha do título, o tradutor acentua certos traços do romance: a despedida, a separação, o fim da convivência, a perda de contato direto entre pessoas e, indiretamente, a morte.

${ }^{3}$ Esta palavra provém de Till Eulenspiegel (o sobrenome significa literalmente traduzido: espelho da coruja), personagem malandro da cultura popular alemã, que surgiu no fim da Idade Média, uma espécie de Pedro Malazarte germânico, o qual, com suposta ingenuidade, leva a sério locuções e metáforas correntes, desmascarando hipocrisias e zombando das pessoas, especialmente das camadas sociais superiores. Vêm daí as palavras francesas espiègle (fino, travesso, malicioso) e espièglerie (finura, travessura, malícia).

${ }^{4}$ Junker é uma denominação, por vezes depreciativa, dos integrantes da nobreza rural na Prússia, latifundiários e/ou militares, considerados por muita gente reacionários e militaristas. O barão von Stechlin destoa dessa imagem, sendo um aristocrata liberal, cético, tolerante, crítico - e empobrecido. Brandenburg foi a região nuclear da antiga Prússia, sendo hoje um dos 16 Estados da República Federal da Alemanha.

Scientia Traductionis, $n .14,2013$ http://dx.doi.org/10.5007/1980-4237.2013n14p247 
${ }^{5}$ No registro culto da língua alemã, o subjuntivo, sobretudo o Konjunktiv I, é comumente usado no discurso indireto, com a função de transferir a responsabilidade pela veracidade do enunciado ao informante, e não àquele que escreve ou fala. Se o emissor utilizar o indicativo, mostra que acredita em tudo o que o informante disse ou escreveu. De modo geral, esse não é o caso do Conselheiro Aires. Além disso, o uso do Konjunktiv I é expressão de um estilo elevado, da norma culta do alemão, usado principalmente na língua escrita.

${ }^{6}$ Palavra citada em português. A lingua alemã não dispõe de um equivalente capaz de cobrir o amplo leque semântico que essa palavra-chave tem na língua portuguesa e na obra de Machado. O correspondente clássico Anmut, é de um registro bastante elevado e soa ligeiramente antiquado, evocando concepções estéticas tradicionais. Seria desejável manter, na tradução de todas as 36 ocorrências de graça no romance, um idêntico correspondente, para garantir a isotopia do original e o lugar de destaque do termo, o que, porém, a língua alemã não permite.

Tradução de:

Simone Homem de Mello simonehomemdemello@gmail.com Casa Guilherme de Almeida - Centro de Estudos de Tradução Literária

Fonte: Machado de Assis, Joaquim Maria. Tagebuch des Abschieds. Tradução de Berthold Zilly. Berlin: Friedenauer Presse, 2009. 